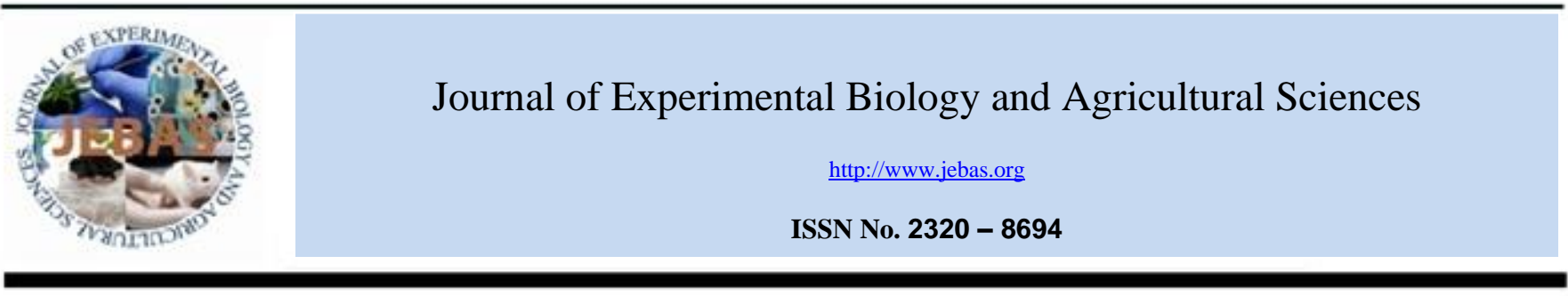

\title{
DYSTOCIA DUE TO FETAL MALDISPOSITION AND MALPRESENTATION IN A NAGALAND MITHUN (Bos frontalis)
}

\author{
Borkotoky $\mathrm{D}^{1}$, Perumal $\mathrm{P}^{2, *}$, Chang $\mathrm{S}^{2}$, Brijesh Kumar $^{3}$, Savino $\mathrm{N}^{4}$ and Sangma CTR ${ }^{4}$ \\ ${ }^{1}$ Porba Regional Centre, ICAR-National Research Centre on Mithun Porba, Nagaland - 797107 \\ ${ }^{2}$ ICAR-National Research Centre on Mithun, Medziphema, Nagaland - 797106 \\ ${ }_{3}^{3}$ ICAR- ICAR Research Complex for NEH Region, Sikkim Centre, Sikkim-737 103, India \\ ${ }^{4}$ NU-School of Agricultural Science and Rural development, Medziphema, Nagaland-797106, India
}

Received - August 05, 2016; Revision - October 03, 2016; Accepted - October 25, 2016

Available Online - October 30, 2016

DOI: http://dx.doi.org/10.18006/2016.4(Spl-3-ADPCIAD).S75.S77

\section{KEYWORDS \\ Mithun \\ Maldisposition and \\ malpresentation \\ Caesarean section}

\section{ABSTRACT}

This short communication of a case report of dystocia in a pluriparous Nagaland mithun strain was due to fetal maldisposition and malpresentation. Severe left lateral deviation of head and neck and dorsopubic-anterior presentation of the fetus caused the maldisposition in Nagaland mithun strain. It was successfully removed with caesarean section and the animal recovered uneventfully.
* Corresponding author

E-mail: perumalponraj@gmail.com(Perumal P)

Peer review under responsibility of Journal of Experimental Biology and Agricultural Sciences.

Production and Hosting by Horizon Publisher India [HPI] (http://www.horizonpublisherindia.in/).

All rights reserved.
All the article published by Journal of Experimental Biology and Agricultural Sciences is licensed under a Creative Commons Attribution-NonCommercial 4.0 International License Based on a work at www.jebas.org.

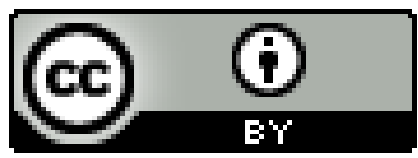




\section{Introduction}

The mithun is a unique bovine found in some of the North Eastern states and are four particular strains in Indian subcontinent namely Nagaland, Arunachal, Mizoram and Manipur strain. A small number of mithun is reported in neighbouring countries such as Bhutan, Myanmar, Yunan province of China and Bangladesh and believed to be a descendent of wild gaur (Simoons, 1984). In general, mithun is reared in free-range system as the traditional practice and the mithun farmers/owners rear their mithun in the village community jungles and forest in group or herd. In general, no reproductive problem was reported in the free ranging mithun rearing forest areas, but some reports were observed in the semi-intensive mithun farm (Perumal et al., 2012; Perumal et al., 2013a; Perumal et al., 2013b). Deviation of the neck and head are very common group of abnormal posture in anterior presentation resulting difficult in birth in different livestock animal species (Roberts, 1971).

The present abnormal deviation may be observed and corrected in any directions and lateral deviation of the neck and head is reported very commonly in unipara and the prognosis of these types case is very serious especially when the deviations are due to muscle contractures and the fetus is dead in bovine species (Sane et al., 1994). The reproductive problem such as dystocia is very rare in this bovine species when compared to other bovine and bubaline species and moreover no such report was observed regarding the dystocia in this precious species and its successful management using caesarean section. Therefore the present case report keeps on record a case of dystocia due to lateral deviation of head and neck and dorsopubic-anterior presentation and its management in Nagaland mithun strain.

\section{History and clinical examination}

A Nagaland mithun of age 6 year was attended at Porba village, Phek District, Nagaland with a history of reduced feed intake, discomfort and a soiled white cord hanging from vagina. The respiration, temperature and pulse were slightly increased. Drooling of saliva from mouth and dry muzzle and congested conjunctival mucus membranes were observed in the present case. Birth canal was dry and oedematous, a fully dilated cervix with hard in consistency and the foul smelling foetal fluids were observed through per-vaginal examination.

The foetus was in dorso pubic position with anterior longitudinal presentation with severe lateral deviation of neck and head and the dead fetus was diagnosed. Finally the case was diagnosed as severe fetal dystocia because of dorso-pubicanterior presentation and severe left lateral deviation of neck and head based on per rectal and per vaginal examination. Fertile and hard attempts were done to relieve the fetus using mutational operation, but no fruitful result. Therefore the caesarean section was performed to relieve the fetus.

\section{Treatments and Discussion}

Epidural anaesthesia (2\% Lignocaine $\mathrm{HCl} ; 7 \mathrm{ml}$ ) was given followed by the animal was properly restrained in right lateral recumbency and left lower flank was prepared for caesarean section. 2\% lignocaine $\mathrm{HCl}$ was for local infiltration and caesarean section completed as per prescribed surgical protocol. A male dead emphysematous fetus was removed with affected fetal membranes from the uterus in the section. Surgical site was properly closed and dressed with care as per standard surgical procedure. General post operative care was provided and the uneventfully animal was recovered.

In this case report, the fetal mal-disposition and malpresentation resulted dystocia, improper and lack of timely intervention leads to fetal death and finally emphysema. Johanson \& Berger (2003) reported $49 \%$ of perinatal mortality was related with unassisted births/delivery. Following death of fetus within 1-3 days, there was invasion of microorganisms from the lower reproductive tract (vagina) resulted dead foetuses with emphysema (Purohit \& Mehta, 2006). Similarly, in the present case report, the fetus was emphysematous, uterine wall contracted around the fetus, the vaginal canal was dry and the vaginal discharge was foetid and watery.

All these observation indicated that death of foetal would have occurred from 1 to 3 days prior to the surgical caesarean section. The fetal mal-dispositions were associated with emphysema of the foetus, deep incision on the foetus to release the gas and forced traction and partial fetotomy can relieve dystocia as in the present study (Purohit et al., 2012; Perumal et al., 2013c). In the present dystocia case report, caesarean section was performed because other fertile attempts failed to relieve/correct the dystocia and further the health of the dam was determined as fair to withstand caesarean section.

\section{Acknowledgements}

The authors are thankful to the Director, ICAR- National Research Centre on Mithun, Jharnapani, Nagaland, India for providing necessary facilities to carry out the research work.

\section{Conflict of interest}

Authors would hereby like to declare that there is no conflict of interests that could possibly arise.

\section{References}

Johanson JM, Berger PJ (2003) Birth weight as a predictor of calving ease and perinatal mortality in Holstein cattle. Journal of Dairy Science 86: $3745 \quad$ - $55 . \quad$ DOI: http://dx.doi.org/10.3168/jds.S0022-0302(03)73981-1

Perumal P, Chamuah JK, Krishanppa B, Vupru K, Khate K (2012) Retention of placenta in mithun crossbred cow (Phre) - 
A Case Report. Veterinary World 6: $171 . \quad$ Purohit GN, Mehta JS (2006) Dystocia in cattle and buffaloes. doi:10.5455/vetworld.2013.171. A retrospective analysis of 156 cases. Veterinary Practitioner 7: $31-34$.

Perumal P, Vupru K, Brijesh Kumar, Rajkhowa C (2013c) Fetal dystocia in a Manipuri Mithun (Bos frontalis) -a case report. Indian Veterinary Journal 90: 71-72.

Perumal P, Vupru K, Khate K, Chamuah JK (2013b) Dystocia due to bilateral shoulder flexion in a Nagaland swamp buffalo. International Journal of Livestock Research 3 : 191-192.

Perumal P, Vupru K, Khate K, Rajkhowa C (2013a) Retention of placenta in mithun (Bos frontalis) cow. International Journal of Livestock Research 3 : 185-190.

Purohit GN, Kumar P, Solanki K, Shekhar C, Yadav SP (2012) Perspectives of fetal dystocia in cattle and buffalo. Veterinary Science Development 2: e831 - e841.
Roberts SJ (1971). Veterinary Obstetrics and Genital Diseases. $2^{\text {nd }}$ edn. CBS Publishers and Distributors, New Delhi, India.

Sane CR, Despande BR, Kaikini AS, Velhankar DP, Kodagali SB, Luktuke SN, Hukeri VB, Deopurkar VL (1994) A Textbook of Reproduction in Farm Animals, $2^{\text {nd }}$ edn., Varghese Publishing House, Mumbai.

Simoons FJ (1984) Gayal or Mithun. In: Mason IL (Ed) Evolution of domesticated animals, Longman, London, UK. pp. 34 . 